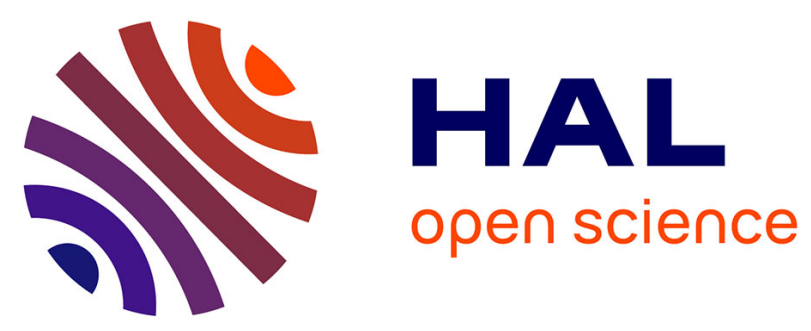

\title{
Once-daily etravirine/raltegravir (400/800 mg q24h) dual therapy maintains viral suppression over 48 weeks in HIV-infected patients switching from a twice-daily etravirine/raltegravir (200/400 $\mathrm{mg} \mathrm{q} 12 \mathrm{~h})$ regimen
}

Romain Palich, Clotilde Allavena, Gilles Peytavin, Cathia Soulié, Roland Tubiana, Laurence Weiss, Ana Montoya Ferrer, Claudine Duvivier, Olivier Bouchaud, Julie Bottero, et al.

\section{- To cite this version:}

Romain Palich, Clotilde Allavena, Gilles Peytavin, Cathia Soulié, Roland Tubiana, et al.. Once-daily etravirine/raltegravir (400/800 mg q24h) dual therapy maintains viral suppression over 48 weeks in HIV-infected patients switching from a twice-daily etravirine/raltegravir (200/400 $\mathrm{mg}$ q12h) regimen. Journal of Antimicrobial Chemotherapy, 2021, 76 (2), pp.477-481. 10.1093/jac/dkaa423 . hal-03177872

\section{HAL Id: hal-03177872 \\ https://hal.sorbonne-universite.fr/hal-03177872}

Submitted on 23 Mar 2021

HAL is a multi-disciplinary open access archive for the deposit and dissemination of scientific research documents, whether they are published or not. The documents may come from teaching and research institutions in France or abroad, or from public or private research centers.
L'archive ouverte pluridisciplinaire HAL, est destinée au dépôt et à la diffusion de documents scientifiques de niveau recherche, publiés ou non, émanant des établissements d'enseignement et de recherche français ou étrangers, des laboratoires publics ou privés. 


\section{Title}

Once-daily etravirine/raltegravir (400/800 mg q24h) dual therapy maintains viral suppression over 48 weeks in HIV-infected patients switching from a twice-daily etravirine/raltegravir (200/400 mg q12h) regimen

\section{Running title}

Etravirine/raltegravir once daily regimen

\section{Authors}

Romain PALICH ${ }^{*}$, Clotilde ALLAVENA², Gilles PEYTAVIN ${ }^{3,4}$, Cathia SOULIE ${ }^{5}$, Roland TUBIANA ${ }^{1}$, Laurence WEISS ${ }^{6}$, Ana MONTOYA FERRER ${ }^{7}$, Claudine DUVIVIER $^{8}$, Olivier BOUCHAUD ${ }^{9}$, Julie BOTTERO ${ }^{10}$, Aurore DURAND ${ }^{11}$, Minh-Patrick LÊ $\hat{E}^{3,12}$, AnneGeneviève MARCELIN ${ }^{3}$, Yasmine DUDOIT ${ }^{1}$, Lambert ASSOUMOU ${ }^{10}$, Christine KATLAMA $^{1}$, on behalf of the ETRAL QD study group $\dagger$

\section{Affiliations}

1. Sorbonne University, Infectious Diseases department, Pitié-Salpêtrière hospital, APHP, Pierre Louis Epidemiology and Public Health institute (iPLESP), INSERM 1136, Paris, France

2. Infectious Diseases department, University hospital, INSERM CIC 1413, Nantes, France

3. AP-HP, Pharmacology-Toxicology department, Bichat-Claude Bernard hospital, Paris, France

4. INSERM, UMR1137, IAME, Université de Paris, Paris, France 
5. Sorbonne University, Virology department, Pitié-Salpêtrière hospital, AP-HP, Pierre Louis Epidemiology and Public Health institute (iPLESP), INSERM 1136, Paris, France

6. Paris Descartes University, Clinical Immunology department, Georges Pompidou hospital, AP-HP, INSERM 976, Paris, France

7. Infectious Diseases department, University hospital, Montpellier, France

8. University of Paris, Infectious Diseases department, Necker-Pasteur Infectiology Center, Necker hospital, AP-HP, INSERM 1016, IHU imagine, Paris, France

9. Infectious Diseases department, Avicenne hospital, AP-HP, Paris, France

10. Infectious Diseases department, Jean Verdier hospital, Paris, France

11. Sorbonne University, Pierre Louis Epidemiology and Public Health institute (iPLESP), INSERM 1136, Paris, France

12. INSERM, UMR_S 1144, Université de Paris, Paris, France

\section{Corresponding author}

Romain Palich, MD

Service des Maladies Infectieuses, hôpital Pitié-Salpêtrière, 47-83 boulevard de l'hôpital, 75013 Paris

Tel.: +33.1.42.16.01.71, fax: +33.1 .42 .16 .04 .45$

Mail: romain.palich@aphp.fr

\section{Words count}

Abstract: 256

Text: 2246 
$\dagger$ Members are listed in the Acknowledgements section. 


\begin{abstract}
Background. Dual therapy etravirine/raltegravir has been shown to be highly effective as twice daily (q12h) regimen in suppressed HIV-infected patients enrolled in the ANRS-163 study. As once daily (q24h) regimen is easier for daily life, we aimed to evaluate the capacity of etravirine/raltegravir $(400 / 800 \mathrm{mg}) \mathrm{q} 24 \mathrm{~h}$ to maintain viral suppression in patients on etravirine/raltegravir q12h.
\end{abstract}

Methods. Patients on suppressive etravirine/raltegravir q12h regimen for at least 96 weeks were switched to etravirine/raltegravir $\mathrm{q} 24 \mathrm{~h}$ in this prospective, multicenter, open-label, single arm study. Primary outcome was the rate of virological failure (VF, confirmed $\mathrm{pVL}>50 \mathrm{copies} / \mathrm{mL}$, single $\mathrm{pVL}>400$ copies/mL or single $\mathrm{pVL}>50$ copies/mL with ART change) at W48. Secondary outcomes included treatment strategy success rate (no VF and no treatment discontinuation), regimen tolerability, plasma drugs concentrations and resistance profile in case of VF.

Results. A total of 111 patients were enrolled, with median (IQR) age: 57 years (52-62), CD4: 710/ $\mathrm{mm}^{3}$ (501-919) and viral suppression: 7.9 years (5.9-10.7). Two patients experienced viral rebound at $\mathrm{W} 24$ and $\mathrm{W} 48$, leading to a VF rate of $2.0 \%(95 \% \mathrm{CI} 0.5-7.8)$ at $\mathrm{W} 48$, associated with INSTI resistance in one case. Both had past NNRTI mutations. Ten patients discontinued treatment for adverse events $(n=2)$, investigator or patient decisions $(n=3)$, lost-to-follow-up $(n=3)$, death $(n=1)$ and pregnancy $(n=1)$. Overall, the strategy success rate was $89 \%$ (95\%CI 81.5-93.6) at W48. In a subgroup of 64 patients, plasma $\mathrm{C}_{24 \mathrm{~h}}$ concentrations were $401 \mathrm{ng} / \mathrm{mL}$ (280-603) for etravirine and $62 \mathrm{ng} / \mathrm{mL}$ (31-140) for raltegravir.

Conclusion. Switching patients virally suppressed on etravirine/raltegravir $\mathrm{q} 12 \mathrm{~h}$ to same regimen given $\mathrm{q} 24 \mathrm{~h}$ was highly effective in maintaining virological suppression in HIVinfected patients. 


\section{INTRODUCTION}

In a context of life long antiretroviral treatment (ART), reducing the cumulated exposure to antiretroviral drugs is one of the key challenges of ART, without derogating to the dogma of undetectability of plasma viral load (pVL), which is the only condition today to insure the best survival, an optimal quality of life, with no risk of viral transmission. ${ }^{1}$ Dual therapies such as dolutegravir/lamivudine (DTG/3TC) $)^{2}$, dolutegravir/rilpivirine (DTG/RPV) ${ }^{3}$ or more recently the long acting strategy with cabotegravir/rilpivirine $(\mathrm{CAB} / \mathrm{RPV})^{4}$ are highly effective in virally suppressed patients, and gradually enter the international guidelines.

In order to investigate alternative strategies to NRTIs- or PIs-based regimen in patients $\geq 45$ years with a long past history of ART, we selected etravirine, as it was, at that time, the only second generation NNRTI, to be the companion drug to raltegravir in the ANRS-163 ETRAL trial (ClinicalTrials.gov identifier: NCT02212379). This dual therapy etravirine/raltegravir given as twice daily regimen (200/400 mg q12h) has been highly effective in maintaining pVL suppression in $99.4 \%$ and $98.7 \%$ of participants at week 48 and week 96 , respectively, with an improvement in lipid profile. ${ }^{5}$

However, as once daily regimen is a simpler, more appropriate regimen for long life therapy, taking advantage of the potential of both drugs etravirine and raltegravir to be used as once daily drugs separately, ${ }^{6,7}$ we aimed to evaluate whether switching etravirine/raltegravir given as twice daily to a once daily one (400/800 mg q24h) will maintain the viral suppression over 48 weeks.

\section{METHODS}

\section{Study participants}

All HIV-1-infected adults $\geq 18$ years old, with HIV-RNA pVL $<50$ copies/mL under a stable dual orally therapy etravirine/raltegravir $\mathrm{q} 12 \mathrm{~h}$ for at least 96 weeks were eligible in this 
prospective cohort study conducted in 7 clinical sites in France. They were switched from their twice daily regimen given as etravirine $200 \mathrm{mg} \mathrm{q} 12 \mathrm{~h}$ plus raltegravir $400 \mathrm{mg}$ q12h to a once daily regimen given as etravirine $400 \mathrm{mg}$ q24h ( 2 x $200 \mathrm{mg}$ scored tablets) plus raltegravir 800 mg q24h (2 x $400 \mathrm{mg}$ film-coated tablets). A part of study participants had been enrolled in the ANRS-163 ETRAL study.

\section{Study endpoints}

The primary efficacy endpoint was the proportion of participants in the intent-to-treat (ITT) population with virological failure $(\mathrm{VF}$, confirmed $\mathrm{pVL}>50$ copies $/ \mathrm{mL}$ or single $\mathrm{pVL}>400$ copies/mL or single $\mathrm{pVL}>50$ copies/mL with ART change) at week 48 using the Kaplan-Meier estimates. The ITT population consisted of all participants who started etravirine/raltegravir q24h regimen at least once. Secondary efficacy endpoints included the proportion of participants with $\mathrm{pVL} \leq 50$ copies/mL at week 48 using the Kaplan-Meier estimates (all treatments discontinuations were considered as failure whatever the reason); the incidence of genotypic resistance and the antiretroviral drug concentration in case of virological failure; change in weight, BMI, CD4 count and CD4/CD8 ratio; and the distribution of etravirine and raltegravir plasma concentrations on the available data.

\section{Data collection}

Clinical data, pVLs and safety parameters including adverse events (AEs) were collected at baseline (prior to switching from etravirine/raltegravir q12h to q24h), weeks 4, 12, 24 and 48. Weight, body mass index (BMI), CD4 and CD8 counts were collected at baseline and week 48 . Blood samples for pharmacological analysis were collected during the study period $24+/-2$ hours after the last drug intake $\left(\mathrm{C}_{24 \mathrm{~h}}\right)$ in a subgroup of patients. Plasma concentrations of etravirine and raltegravir were determined by ultra-performance liquid chromatography 
coupled with tandem mass spectrometry (UPLC-MS/MS; Waters Acquity UPLC-TQD, Milford, MA). ${ }^{8}$

The limit of quantification was $<5 \mathrm{ng} / \mathrm{ml}$ for both drugs, and interpretation was based on the corresponding in vitro protein-adjusted 95\% inhibitory concentration ( $\mathrm{PBIC}_{95}$ ) for wild-type (WT) HIV-1: $116 \mathrm{ng} / \mathrm{ml}$ for etravirine ${ }^{9}$ and $15 \mathrm{ng} / \mathrm{ml}$ for raltegravir. ${ }^{10}$ Etravirine and raltegravir $\mathrm{C}_{24 \mathrm{~h}}$ were considered to be adequate if above the respective PBIC95. Results of pooled $\mathrm{C}_{24 \mathrm{~h}}$ of etravirine and raltegravir over the study period are presented as median (interquartile range $[\mathrm{IQR}])$ values and compared with the historical data of $\mathrm{q} 12 \mathrm{~h}$ regimen. ${ }^{8}$

\section{Statistical analysis}

The 95\% confidence intervals of the proportion of participants with virological failure and treatment success were calculated with Kalbfleisch and Prentice's formula. The non-parametric Wilcoxon paired test were used to compare the change from baseline in weight, CD4 count and $\mathrm{CD} 4 / \mathrm{CD} 8$ ratio. All treatment discontinuations were described and frequency were reported. All p-value are two-sided with a significant level of 0.05 . The analysis was performed using SAS ${ }^{\circledR}$ statistical analysis software version 9.4 for Windows.

\section{Ethics}

The protocol was reviewed and approved by the national Ethics Committee Est 4 (approval $\# 17 / 50$ ) and all participants were informed and not opposed to the collection of their data.

\section{RESULTS}

Study population 
Between 09/2017 and 06/2018, 113 patients from 7 French sites were screened. Two patients did not fulfill inclusion criteria (under etravirine/raltegravir q12h for less than 96 weeks), leaving 111 patients for analysis.

Participants' baseline characteristics are shown in Table 1. Median age was 57 years (IQR 5262). They were virologically suppressed on ART for a median duration of 7.9 years (IQR 5.910.7). The median duration of raltegravir/etravirine $\mathrm{q} 12 \mathrm{~h}$ was 29 months (IQR 26-40).

Fifty-one out of 111 patients (46\%) had been previously included in the ANRS-163 ETRAL trial. These patients had broadly the same characteristics of the total study population on etravirine/raltegravir q24h, with the exception of a younger age (52 vs. 57 years) and a shorter time from HIV diagnosis (17 vs. 24 years).

\section{Virological and strategy success rates at W48}

Overall, 99/111 patients had a $\mathrm{pVL} \leq 50$ copies/mL at W48. With two protocol-defined VF occurring during the study follow-up of 48 weeks, the virological success rate was $98.0 \%$ (95\%CI 92.2-99.5) and the failure rate was $2.0 \%(95 \% \mathrm{CI} 0.5-7.8)$ at W48 (Figure 1a et $1 \mathrm{~b})$.

One VF occurred at week 24 with 2 values of $\mathrm{pVL}$ of 7,950 and 5,440 copies/mL concomitantly with low plasma $\mathrm{C}_{24 \mathrm{~h}}$ of etravirine $(99 \mathrm{ng} / \mathrm{mL})$ and adequate $\mathrm{C}_{24 \mathrm{~h}}$ of raltegravir $(34 \mathrm{ng} / \mathrm{mL})$, leading to the emergence of resistance mutations associated to INSTI (L74I, G140A and Q148H). Past HIV-RNA genotypes showed a B subtype with the presence of K103N and 100I mutations (in 2000, 2001, 2003 and 2017), which could decrease the etravirine viral potency (2019 ANRS algorithm, v.30). The patient was resuppressed under a dual therapy combining etravirine (400 mg q24h) + darunavir/ritonavir (800/100 mg q24h). The second VF occurred at W48 with only one pVL value of 156 copies/mL, that lead to ART change, with concomitant adequate plasma $\mathrm{C}_{24 \mathrm{~h}}$ for etravirine $(367 \mathrm{ng} / \mathrm{mL})$ and raltegravir $(102 \mathrm{ng} / \mathrm{mL})$, and no emergence of resistance. Past HIV-RNA genotypes displayed an A1 subtype with several NNRTI- 
associated resistance mutations (A98G, K101R and G190E/Q), which may reduce the viral potency of etravirine (2019 ANRS algorithm, v.30). Viral resuppression was achieved on dolutegravir/rilpivirine (50/25 mg q24h) + lamivudine (300 mg q24h).

Overall, 10 (9.0\%) etravirine/raltegravir q24h discontinuations had occurred for reasons other than VF: mild adverse events $(n=2)$, investigator decisions $(n=2)$, patient decision $(n=1)$, death due to myocardial infarction $(n=1)$, lost-to-follow-up $(n=3)$ and pregnancy $(n=1)$ leading to a final strategy success rate of $89.0(95 \%$ CI 81.5-93.6) at W48. The two patients with adverse events (nausea, headache) remained under etravirine/raltegravir dual therapy but in q12h rather than $\mathrm{q} 24 \mathrm{~h}$ regimen without obvious reason. No plasma drugs concentrations were available for these patients.

\section{Pharmacological outcomes}

In the present study, 64 patients had plasma concentrations determinations under etravirine/raltegravir $\mathrm{q} 24 \mathrm{~h}$ over the study period. Median (IQR) $\mathrm{C}_{24 \mathrm{~h}}$ values of etravirine and raltegravir were $401 \mathrm{ng} / \mathrm{mL}(280-603)$ and $62 \mathrm{ng} / \mathrm{mL}$ (31-140), respectively (Figure 2a and 2b). In this $\mathrm{q} 24 \mathrm{~h}$ regimen, median interpatient variabilities of $\mathrm{C}_{24 \mathrm{~h}}$ were $56 \%$ and $219 \%$ for etravirine and raltegravir, respectively. Only 3 patients presented etravirine $\mathrm{C}_{24 \mathrm{~h}}<116 \mathrm{ng} / \mathrm{mL}$ and 3 other patients raltegravir $\mathrm{C}_{24 \mathrm{~h}}<15 \mathrm{ng} / \mathrm{mL}$. None presented both etravirine and raltegravir suboptimal $\mathrm{C}_{24 \mathrm{~h}}$

\section{Clinical and immunological outcomes at W48}

There was no significant change in body weight: $-1.0 \mathrm{~kg}(-2.5$ to $2.0, \mathrm{p}=0.41)$, nor in BMI: -0.3 ( -0.8 to $0.7, \mathrm{p}=0.45)$, in the 75 patients for whom the weight was precisely measured at D0 and W48. Moreover, among 41 patients who had been included in the ANRS-163 ETRAL study, overall weight change under etravirine/raltegravir $\mathrm{q} 12 \mathrm{~h}$ was $+2.0 \mathrm{~kg}(\mathrm{IQR}-1.0$ to $5.0, \mathrm{P}=0.031)$ 
after a median time of 119 weeks (IQR 110-124). However, after switching to etravirine/raltegravir q24h, the weight remained stable with a median change of -1.0 $\mathrm{kg}$ (IQR 2.5 to $2.0, \mathrm{P}=0.44) 48$ weeks later.

There was no significant change in CD4 count: +2.5 cells $/ \mathrm{mm}^{3}$ (IQR -72 to $84, \mathrm{p}=0.75$ ), and in CD4/CD8 ratio: $+0.03(-0.07$ to $0.10, \mathrm{p}=0.16)$.

\section{DISCUSSION}

This open label observational study shows that etravirine/raltegravir (200/400 $\mathrm{mg})$ regimen given twice daily could be safely switched to a once daily regimen in participants virally suppressed, with a virological success rate of $98.0 \%$ at W48. This was supported by previous works included etravirine and raltegravir given separately once daily in different 3-drug regimens. ${ }^{6,7}$

Dual suppressive therapies are increasingly important in a context of long life needed ART. The benefit of the etravirine/raltegravir combination in an aging population has been shown in the ANRS-163 ETRAL study. ${ }^{5}$ Especially, the participants had improved their lipid profile and their bone mineral density after stopping boosted protease inhibitors and tenofovir, that could avoid cardiovascular and bone fracture risks. Prevention of antiretrovirals toxicities is a key concern for aging people living with HIV. A part of the participants included in our study had been enrolled in the ANRS-163 ETRAL study, and our population was a little older, with a median age of 57 years. We hypothesize that the benefits of the etravirine/raltegravir combination was sustained in this population when given once daily, in addition to improving the quality of life. However, as most of these patients had comedications, once daily regimen is not necessarily the best option. In our study, three patients decided to return to a twice daily taken, two of them because of nausea or headache, and the third one for more comfort. We can 
assume that the maximum plasma drugs concentrations are higher in $\mathrm{q} 24 \mathrm{~h}$ than in $\mathrm{q} 12 \mathrm{~h}$, perhaps explaining the two side effects, but no pharmacological data support this hypothesis.

The pharmacological results of the present once daily study are consistent with those of the previous twice daily study, providing adequate plasma exposure and confirming the lack of relevant clinical drug interaction and the complementary pharmacokinetic profiles of both drugs. As a reminder, from the ANRS-163 ETRAL study, 103 patients had plasma concentrations performed under etravirine/raltegravir $\mathrm{q} 12 \mathrm{~h}$; median (IQR) $\mathrm{C}_{12 \mathrm{~h}}$ values of etravirine $200 \mathrm{mg} \mathrm{q} 12 \mathrm{~h}$ and raltegravir $400 \mathrm{mg} \mathrm{q} 12 \mathrm{~h}$ were $586 \mathrm{ng} / \mathrm{mL}(434-819)$ and $267 \mathrm{ng} / \mathrm{mL}$ (111-737), respectively. ${ }^{8}$ Only 3 patients presented both etravirine and raltegravir $\mathrm{C}_{12 \mathrm{~h}}$ less than respective $\mathrm{PBIC}_{95}$. In this $\mathrm{q} 12 \mathrm{~h}$ regimen, median interpatient variabilities of $\mathrm{C}_{12 \mathrm{~h}}$ were $45 \%$ and $166 \%$ for etravirine and raltegravir, respectively. Due to the long elimination half-life of etravirine, the respective trough plasma concentration values in both regimens are close. On the other hand, as expected, those of raltegravir are much lower in $\mathrm{q} 24 \mathrm{~h}$ than in $\mathrm{q} 12 \mathrm{~h}$, its elimination half-life being much shorter. Despite this, the inter-individual variabilities of respective trough plasma concentrations for each drug are very comparable between the two dosing regimens, as is the number of values below the respective $\mathrm{PBIC}_{95}$. All these pharmacological results are in favor of a good antiviral efficacy of this maintenance dual once daily regimen in plasma but also in compartments.

There were two virological failures, including one with concomitant low etravirine plasma concentrations; INSTI associated resistance emerged in this patient. However, we cannot exclude that this mutation was present at baseline as a polymorphism. The integrase gene had not been sequenced on past genotypes, and no sample was available to perform a genotype before the virological failure. The second virological failure consisted in an uncontrolled single $\mathrm{pVL}<200$ copies $/ \mathrm{mL}$, with adequate plasma exposure of both drugs and no emergence of 
resistance. Both had prior NNRTI associated resistance mutations, suggesting that this dual therapy should be avoided in case of resistance mutations impacting etravirine.

Body weight increasing has become a crucial issue under INSTI, in naïve patients and pretreated patients. ${ }^{9,10}$ This body weight increasing seems to be higher under dolutegravir than elvitegravir/cobicistat or raltegravir. Moreover, in vitro physiopathological explorations tends to show that adipogenesis abnormalities are stronger under dolutegravir than raltegravir. ${ }^{11}$ In our study performed in patients pretreated with etravirine/raltegravir q12h, we did not observe any significant additional body weight gain under etravirine/raltegravir q24h over 48 weeks.

Although other dual therapies are currently widely used, it seems essential to evaluate alternative strategies. Dual therapies without rilpivirine and without dolutegravir may be preferred in patients on proton pump inhibitors or metformin, for example, due to drug-drug interactions. A combination of raltegravir and the recent NNRTI doravirine may be a good option, but no data on this combination is currently available.

Our study has some limitations, including the absence of a comparator arm. Indeed, a single arm non-randomized trial tends to result in larger estimated treatment effects and is susceptible to high dropout and discontinuation. However, the number of enrolled patients was enough to allow the assessment of virological success with sufficient precision. No extensive sub-studies (metabolic profiles, inflammation) have been performed, the benefit of switching for etravirine/raltegravir regimen having already been demonstrated in the ANRS-163 ETRAL study. The new formulation of raltegravir (1200 mg q24h) was not available when this study was designed, explaining the dosage we have used (800 mg q24h).

In conclusion, there is a clear need for investigation of drug-reduced antiretroviral strategies targeting lifelong viral suppression, minimizing drug exposure and drug-drug interactions, particularly in an aging population. A dual therapy combining raltegravir and etravirine, given 
once daily, represents a highly effective and safe strategy. Doravirine deserve to be investigated in association with raltegravir.

\section{ACKNOWLEDGMENT}

ETRAL QD study group: C. Allavena, F. Raffi, M. Cavellec, A. Soria, E. Paredes Manyari, J. Reynes, A. Montoya Ferrer, C. Tramoni, C. Fernandez, C. Duvivier, J. Lourenço, C. Louisin, F. Touam, O. Bouchaud, L. Traore, J. Bottero, F. Mfutila Kaykay, A. Benmammar, L. Weiss, J. Effa, M. Ptak, M. A. Valantin, R. Tubiana, L. Schneider, C. Blanc, L. Lenclume.

This work has been presented as a poster at the Conference on Retroviruses and Opportunistic Infections (CROI), 2020, Boston, USA (Abs. 0494).

\section{FUNDING}

This study was supported by internal funding.

\section{TRANSPARENCY DECLARATION}

RP has received travel grants from Gilead, ViiV Healthcare, Janssen and Merck. CA has received honoraria from Gilead, ViiV Healthcare, Merck and Janssen. GP has received travel grants, consultancy fees, honoraria or study grants from Gilead, Merck, Theratechnologie and ViiV Healthcare. LW has received a research grant from Pfizer and fees from Merck for lectures and participation in a scientific board. CD has received consultancies, honoraria, paid expert testimony and travel grants from Gilead, Janssen, Merck and ViiV Healthcare. MPL has received travel grants from Bristol-Myers-Squibb and Janssen. AGM. has received 
honoraria and travel grants from ViiV Healthcare, Janssen, Gilead and Merck. CK has received honoraria from ViiV Healthcare, Merck and Janssen. CS, RT, AMF, OB, JB, AD, YD and LA have any conflicts of interest to declare. 


\section{REFERENCES}

1. Katlama C, Ghosn J, Murphy RL. Individualized antiretroviral therapeutic approaches: less can be more. AIDS Lond Engl 2017; 31: 1065-71.

2. van Wyk J, Ajana F, Bisshop F, et al. Efficacy and Safety of Switching to

Dolutegravir/Lamivudine Fixed-Dose Two-Drug Regimen Versus Continuing a Tenofovir Alafenamide-Based Three- or Four-Drug Regimen for Maintenance of Virologic Suppression in Adults With HIV-1: Phase 3, Randomized, Non-inferiority TANGO Study. Clin Infect Dis Off Publ Infect Dis Soc Am 2020; ciz1243.

3. Llibre JM, Hung C-C, Brinson C, et al. Efficacy, safety, and tolerability of dolutegravirrilpivirine for the maintenance of virological suppression in adults with HIV-1: phase 3, randomised, non-inferiority SWORD-1 and SWORD-2 studies. Lancet Lond Engl 2018; 391: 839-49.

4. Swindells S, Andrade-Villanueva J-F, Richmond GJ, et al. Long-Acting Cabotegravir and Rilpivirine for Maintenance of HIV-1 Suppression. N Engl J Med 2020; 382: 1112-23.

5. Katlama C, Assoumou L, Valantin M-A, et al. Dual therapy combining raltegravir with etravirine maintains a high level of viral suppression over 96 weeks in long-term experienced HIV-infected individuals over 45 years on a PI-based regimen: results from the Phase II ANRS 163 ETRAL study. J Antimicrob Chemother 2019; 74: 2742-51.

6. Gazzard B, Duvivier C, Zagler C, et al. Phase 2 double-blind, randomized trial of etravirine versus efavirenz in treatment-naive patients: 48-week results. AIDS Lond Engl 2011; 25: $2249-58$.

7. Vispo E, Barreiro P, Maida I, et al. Simplification from protease inhibitors to once- or twice-daily raltegravir: the ODIS trial. HIV Clin Trials 2010; 11: 197-204.

8. Lê MP, Valantin M-A, Assoumou L, et al. Lack of a Clinically Significant Pharmacokinetic Interaction between Etravirine and Raltegravir Using an Original Approach 
Based on Drug Metabolism, Protein Binding, and Penetration in Seminal Fluid: A Pharmacokinetic Substudy of the ANRS-163 ETRAL Study. Pharmacotherapy 2019; 39: 514-20.

9. Lake JE, Wu K, Bares SH, et al. Risk Factors for Weight Gain Following Switch to Integrase Inhibitor-Based Antiretroviral Therapy. Clin Infect Dis Off Publ Infect Dis Soc Am 2020; ciaa177.

10. Eckard AR, McComsey GA. Weight gain and integrase inhibitors. Curr Opin Infect Dis 2020; 33: 10-9.

11. Gorwood J, Bourgeois C, Pourcher V, et al. The integrase inhibitors dolutegravir and raltegravir exert pro-adipogenic and profibrotic effects and induce insulin resistance in human/simian adipose tissue and human adipocytes. Clin Infect Dis Off Publ Infect Dis Soc Am 2020; ciaa259. 
Table 1. Population characteristics at baseline and during follow-up

\begin{tabular}{|c|c|}
\hline & Total $\mathrm{N}=111$ \\
\hline Age, years, median (IQR) & $57(52-62)$ \\
\hline \multicolumn{2}{|l|}{ Gender - n (\%) } \\
\hline - Men & $85(76.6)$ \\
\hline - Women & $26(23.4)$ \\
\hline \multicolumn{2}{|l|}{ Origin $-\mathrm{n}(\%)$} \\
\hline - Caucasian & $83(74.8)$ \\
\hline - Sub-saharan Africa & $12(10.8)$ \\
\hline - Other & $16(14.4)$ \\
\hline \multicolumn{2}{|l|}{ Transmission group $-\mathrm{n}(\%)$} \\
\hline - $\mathrm{MSM}$ & $56(50.5)$ \\
\hline - $\quad$ IV drug users & $10(9.0)$ \\
\hline - Heterosexual & $35(31.5)$ \\
\hline - Other & $10(9.0)$ \\
\hline HIV diagnosis, years, median (IQR) & $24.4(18.6-28.4)$ \\
\hline $\begin{array}{l}\text { Etravirine/raltegravir BID duration, months, } \\
\text { median (IQR) }\end{array}$ & $29(6-40)$ \\
\hline CD4 nadir, cells $/ \mathrm{mm}^{3}$, median (IQR) & $183(90-269)$ \\
\hline $\begin{array}{l}\text { Pretherapeutic } \mathbf{p V L}, \log _{10} \text { copies } / \mathrm{mL} \text {, } \\
\text { median (IQR), } \mathrm{n}=53\end{array}$ & $4.7(4.2-5.2)$ \\
\hline CDC C $-\mathrm{n}(\%)$ & $34(30.6)$ \\
\hline $\begin{array}{l}\text { Duration of virological suppression, years, median } \\
(\mathrm{IQR}), \mathrm{n}=109\end{array}$ & $7.9(5.9-10.7)$ \\
\hline CD4, cells $/ \mathrm{mm}^{3}$, median (IQR), $\mathrm{n}=104$ & $710(501-919)$ \\
\hline CD4/CD8 ratio, cells $/ \mathrm{mm}^{3}$, median (IQR), $\mathrm{n}=102$ & $0.93(0.66-1.27)$ \\
\hline
\end{tabular}


Figure 1. Virological success rate (A) and treatment success rate (B) under etravirine/raltégravir QD at week 48.

A. Virological success

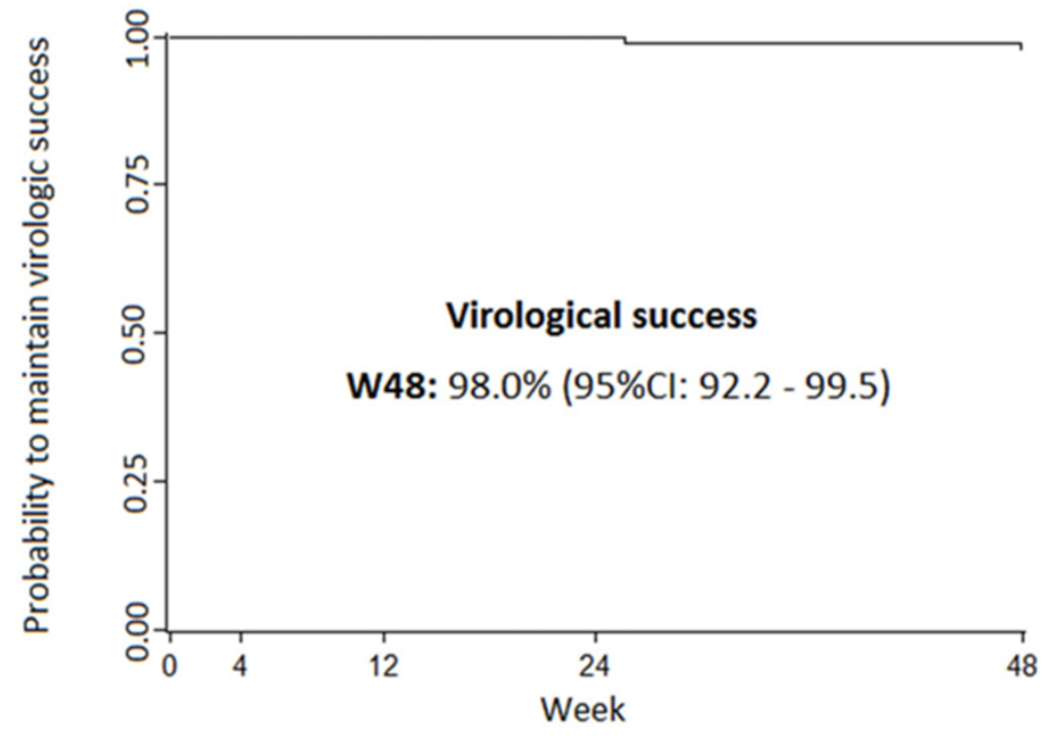

$\begin{array}{lllll}\text { Number at risk } & 111 & 110 & 108 & 104\end{array}$

B. Treatment success

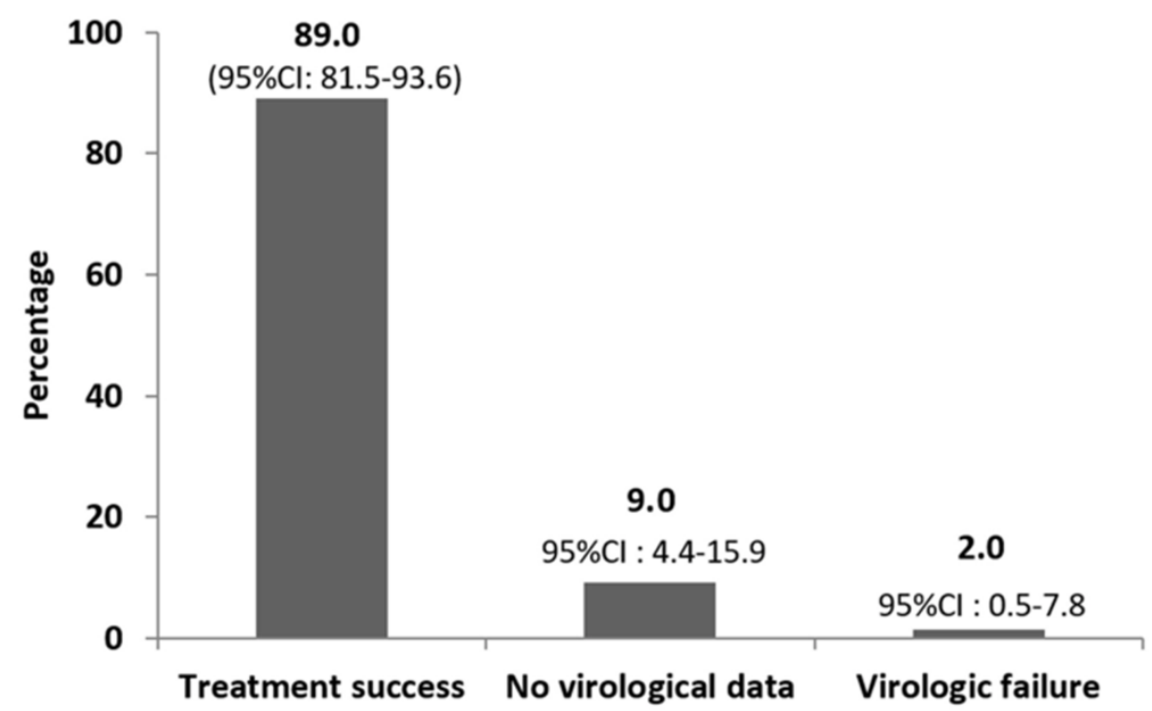


Figure 2. Pooled Plasma concentrations $\left(\mathrm{C}_{12 \mathrm{~h}}\right.$ and $\left.\mathrm{C}_{24 \mathrm{~h}}\right)$ of etravirine (a) and raltegravir (b) (ng/mL) for BID and QD dosing regimen between W4 and W48, respectively. BID data were from ANRS-163 ETRAL study. ${ }^{8}$ PBIC $_{95}$ : protein-adjusted $95 \%$ inhibitory concentration, WT-HIV-1: wild-type HIV-1.
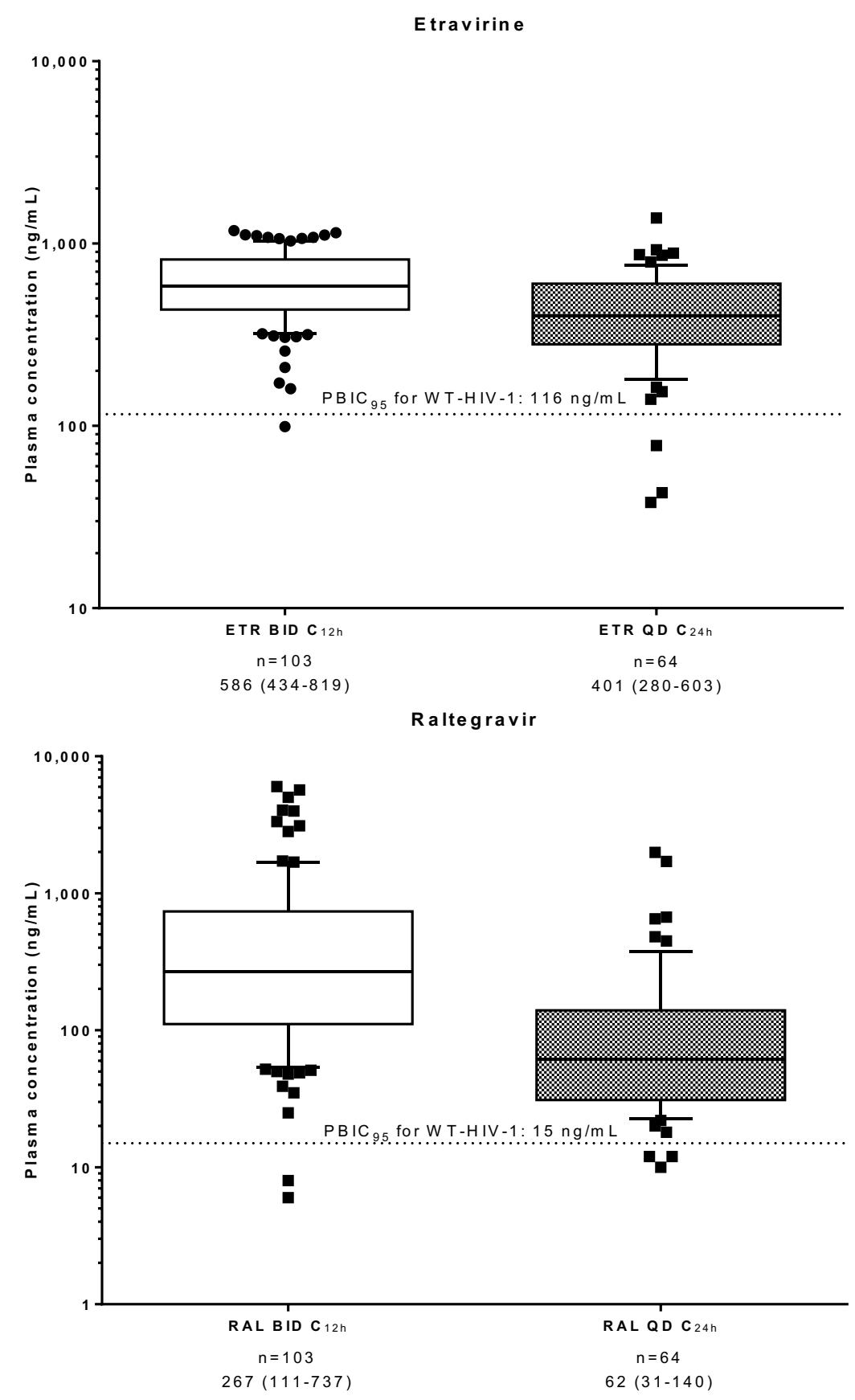